\title{
Dynamics of myocardial adaptation to low-flow ischemia and hypoxemia
}

\author{
GIAMPIERO MERATI, SONIA ALLIBARDI, LUCILLA D. MONTI, \\ JAN WILLEM DE JONG, AND MICHELE SAMAJA \\ Department of Biomedical Science and Technology, University of Milan, Milan I-20090; \\ Scientific Institute H. San Raffaele, Milan I-20132, Italy; and Thorax Center, \\ Erasmus University, 3000 DR Rotterdam, The Netherlands
}

\begin{abstract}
Merati, Giampiero, Sonia Allibardi, Lucilla D. Monti, Jan Willem de Jong, and Michele Samaja. Dynamics of myocardial adaptation to low-flow ischemia and hypoxemia. Am. J. Physiol. 271 (Heart Circ. Physiol. 40): H2300-H2305, 1996.-We investigated whether one or more factors control performance in $\mathrm{O}_{2}$-limited hearts. For this purpose, we measured the dynamics of myocardial adaptation to reduced $\mathrm{O}_{2}$ supply with a specially designed setup, analyzing early changes after reduction in either flow of the perfusion medium or its $\mathrm{PO}_{2}$. For 10 min, 38 isolated rat hearts underwent low-flow ischemia or hypoxemia, matched for $\mathrm{O}_{2}$ supply. Early during ischemia, developed pressure declined at a rate of $311 \pm 25 \mathrm{mmHg} / \mathrm{s}$; lactate release increased and then leveled off to $3.4 \pm 0.7 \mu \mathrm{mol} / \mathrm{min}$ within $2 \mathrm{~min}$. During hypoxemia, pressure dropped initially, as observed during ischemia. However, it then increased before slowly decreasing. Lactate release during hypoxemia peaked at $13.0 \pm 2.3 \mu \mathrm{mol} / \mathrm{min}$ after $2 \mathrm{~min}$, leveling off to $3.5 \pm 1.3 \mu \mathrm{mol} / \mathrm{min}$. Glycogen decreased by 52 and $81 \%$ in ischemic and hypoxemic hearts, respectively $(P<0.05)$. Reexposure to ischemia or hypoxemia induced comparable changes in both groups. We conclude that, at the beginning of ischemia, a single factor does limit myocardial performance. This variable, which remains undisturbed for $10 \mathrm{~min}$, is presumably $\mathrm{O}_{2}$ availability. In contrast, $\sim 20$ s after induction of hypoxemia, glycolytic ATP production can partially override low $\mathrm{O}_{2}$ availability by providing most of the energy needed. During repeated restriction of $\mathrm{O}_{2}$ supply, $\mathrm{O}_{2}$ availability alone limits performance during both ischemia and hypoxemia.
\end{abstract}

dynamics of adaptation; high-energy phosphates; lactate release

MYOCARDIAL UNDERPERFUSION results in nearly immediate functional decline due to the turnover rates of high-energy phosphates, which are fast in relation to their intracellular concentration (13). Under these conditions, low $\mathrm{O}_{2}$ supply forces the heart to switch from aerobic to less efficient pathways in an attempt to maintain ATP homeostasis. This shift seems crucial in determining reperfusion injury and providing endogenous myocardial protection. However, the mechanisms underlying myocardial responses to $\mathrm{O}_{2}$ deprivation are still obscure, because simultaneously occurring phenomena complicate a clear understanding (19). To gain insight into this issue, we focused on the dynamics of heart adaptation to $\mathrm{O}_{2}$ deprivation.

The rationale underlying our approach is as follows. In principle, myocardial performance is comparable to the "product" of a multistep biochemical sequential process, in which factors such as $\mathrm{PO}_{2}$ and energy stores represent the "reagents." The slowest step, which be- comes the limiting factor, ultimately controls the overall rate of multistep processes. If the adaptation of a biological system to an external stimulus is monophasic, then it is likely that a single factor limits the whole process. On the other hand, if the adaptation is biphasic or multiphasic, several factors presumably control the process, either simultaneously or sequentially.

Few studies have addressed the relevance and sequence of mechanisms underlying myocardial ischemia. Some have described the adaptation to $\mathrm{O}_{2}$ deprivation in the time range of minutes $(15,16,24$, $25)$, but the models employed did not allow extrapolation to the time range of seconds. Others have examined the second-to-second adaptation of muscle or heart to work jumps $(1,5,8,12,20)$ but under conditions of unlimited $\mathrm{O}_{2}$ supply.

It seems worthwhile to compare the effects due to low-flow ischemia at normal $\mathrm{Po}_{2}$ (LFI) with those caused by hypoxemia at normal flow (Hyp) at the same degree of $\mathrm{O}_{2}$ deprivation. Indeed, such an approach has characterized the role of free radicals in determining reperfusion injury (27), lactate in downregulating myocardial function (25), and coronary flow in preserving the ATP pool (26). However, in these studies, data were taken $20 \mathrm{~min}$ after the onset of LFI or Hyp, when factors related to flow prevailed over those related to $\mathrm{O}_{2}$ availability $(5,14,15,30)$.

We studied the dynamics of myocardial adaptation to LFI and Hyp in the seconds range by synchronizing the switch between two media perfusing isolated hearts, with frequent measurements of performance. The media had the same composition but different flow or $\mathrm{O}_{2}$ content to simulate LFI and Hyp, respectively. We show that a single factor presumably governs the changes induced by LFI, whereas during exposure to Hyp, more factors come into play, one of them forming part of an energy store.

\section{MATERIALS AND METHODS}

Heart perfusion. Male Sprague-Dawley rats, weighing 250$280 \mathrm{~g}$ and fed ad libitum, were anesthetized with heparinized thiopental sodium (100 mg/kg ip). Hearts were excised, put into perfusion buffer $\left(20^{\circ} \mathrm{C}\right)$ to facilitate mounting, and immediately perfused in the Langendorff mode with KrebsHenseleit buffer containing $2.0 \mathrm{mM}$ free $\mathrm{Ca}^{2+}$ and $11 \mathrm{mM}$ glucose $\left(\mathrm{pH} 7.4,37^{\circ} \mathrm{C}\right)$. The medium was equilibrated at the desired $\mathrm{PO}_{2}(670$ or $67 \mathrm{mmHg})$ and $\mathrm{PCO}_{2}(43 \mathrm{mmHg})$ in membrane oxygenators. The perfusion system was designed to synchronize fast data acquisition with rapid switches in the perfusing medium by use of a computer-operated valve. Thus two circuits were devised for the same medium, each equipped with separate pump, filter, and membrane oxygen- 
ator. One circuit was set for baseline perfusion (flow $=15$ $\mathrm{ml} / \mathrm{min}, \mathrm{PO}_{2}=670 \mathrm{mmHg}$ ) and the other for either LFI (flow $-1.5 \mathrm{ml} / \mathrm{min}, \mathrm{PO}_{2}=670 \mathrm{mmHg}$ ) or Hyp (flow $=15$ $\mathrm{ml} / \mathrm{min}, \mathrm{PO}_{2}=67 \mathrm{mmHg}$ ). A backpressure of $80-100 \mathrm{mmHg}$, applied to recirculation of the unuscd circuit, prevented undesired adjustments of flow secondary to changes in perfusion pressure and resistance.

A latex balloon in the left ventricle was connected to a pressure transducer (Harvard Apparatus model 52-9966, Natick, MA) to measure heart rate (HR), end-diastolic pressure (EDP), left ventricular developed pressure (LVDP), and maximal rate of pressure development $\left(\mathrm{dP} / \mathrm{d} t_{\max }\right)$. A transducer connected to the aortic cannula provided the coronary perfusion pressure (CPP). The vascular resistance was calculated as (CPP - EDP)/flow per gram of ventricle (6). The venous return was collected by a cannula in the pulmonary artery for measurement of $\mathrm{PO}_{2}$ (Yellow Springs Instruments model 5300 oxygen monitor, Yellow Springs, OH; equipped with Teflon membranes, 0.001-in. nominal thickness). For data acquisition and solenoid valve operation, LabView 3.0 software and a NB-MIO-16 multifunction I/O board (National Instrument, Austin, TX) were implemented, running on an Apple Macintosh Quadra 700 (Cupertino, CA). The application controlled valve switching, monitored myocardial function, and performed background calculations, storing data in work sheets. Data were sampled at 30-s intervals, but sampling rate was $5 \mathrm{~s}$ for 2 min after valve operation.

This system monitored the second-to-second adaptation after the switch in perfusion medium. The short sampling time and negligible incidence of arrhythmias at the onset of LFI and Hyp allowed enough resolution to evaluate early myocardial responses to these interventions. At the onset of reperfusion or reoxygenation, severe arrhythmias made analysis of the dynamics impossible. During the change from baseline to LFI, the valve switching time $(<1 \mathrm{~ms})$ limited response time. When Hyp started, the dead volume of the system was the limiting factor for the response time $(\sim 1.4 \mathrm{~s})$; we corrected our data for this delay. The response time of the $\mathrm{PO}_{2}$ electrode depended on dead volume (aortic cannula to electrode chamber including coronary vasculature, $\sim 0.5 \mathrm{ml}$ ), flow, and intrinsic response time of the device. Despite the use of highly permeable Teflon membranes, the overall response time for $\mathrm{PO}_{2}$ measurements was $-17 \mathrm{~s}$. We therefore caution the reader about this artifact when dealing with the $\mathrm{PO}_{2}$-time curves.

Experimental protocol. Hearts ( $n=38$ ) were stabilized for $20 \mathrm{~min}$ at a flow of $15 \mathrm{ml} / \mathrm{min}$ and a $\mathrm{PO}_{2}$ of $670 \mathrm{mmHg}\left(\mathrm{O}_{2}\right.$ supply $=14.1 \mu \mathrm{mol} \cdot \mathrm{min}^{-1} \cdot$ heart $\left.^{-1}\right)$. The balloon volume was adjusted to achieve an EDP of $\sim 10 \mathrm{mmHg}$; it was kept constant afterward. Hearts underwent two cycles of either LFI or Hyp (10 min, $n=13 /$ group), followed by $10 \mathrm{~min}$ of reperfusion or reoxygenation. LFI and Hyp were obtained by reducing flow to $1.5 \mathrm{ml} / \mathrm{min}$ or $\mathrm{PO}_{2}$ to $67 \mathrm{mmHg}$, respectively, thus matching the two conditions for $\mathrm{O}_{2}$ supply. For metabolic assays, additional hearts were freeze clamped at liquid nitrogen temperature at the end of baseline, LFI, or Hyp ( $n=$ 4/group).

Other measurements. Every $15 \mathrm{~s}$, samples of the venous effluent were obtained from the pulmonary arterial catheter for assaying the lactate concentration (21). Net lactate release $\left(J_{\mathrm{Lac}}\right)$ was calculated as lactate concentration times flow. Tissue $\mathrm{H}_{2} \mathrm{O}$ content was determined by weighing an aliquot of the left ventricle after 24 and $48 \mathrm{~h}$ at $65^{\circ} \mathrm{C}$. Glycogen was assayed in dry tissue after amyloglucosidase digestion (4). The neutralized extract was also analyzed for high-energy phosphates and their metabolites by high-performance liquid chromatography methods (26). The energy charge, calculated as $([\mathrm{ATP}]+0.5[\mathrm{ADP}]) /([\mathrm{ATP}]+[\mathrm{ADP}]+[\mathrm{AMP}])$, is an index of the cardiac ability to use metabolic energy. IMP reflects the heart's metabolic derangement (2). The sum of ATP, ADP, AMP, IMP, adenosine, inosine, hypoxanthine, xanthine, and urate indicates the loss of adenine nucleotides and purines due to the combination of high energy demand and high coronary flow (26).

Statistics. Data are expressed as means \pm SE. When two groups were compared, the Student's $t$-test for unpaired data was used. Comparisons of more than two groups were done by one-way analysis of variance (ANOVA) with either three groups for metabolic data (baseline, LFI, and Hyp) or four groups for recovery data (recovery after 1 st and 2 nd reduction in $\mathrm{O}_{2}$ supply for both LFI and Hyp). Various time courses were compared by ANOVA for repeated measures with four groups for each parameter (1st and 2 nd reduction in $\mathrm{O}_{2}$ supply for both LFI and Hyp). If ANOVA was significant, selected pairs of data were analyzed with Fisher's protected least significant difference test. The significance level was set at $P=0.05$ (2 tailcd).

\section{RESULTS}

Control experiments and baseline data. In two hearts (data not shown), the myocardial "response" to switching between two identical perfusing media was tested. The peak changes in CPP $(<3.3 \mathrm{mmHg})$, EDP $(<4.6$ $\mathrm{mmHg}$ ), LVDP ( $<5.9 \mathrm{mmHg}$ ), and HR ( $<6$ beats $/ \mathrm{min}$ ) accounted for one or occasionally two sampling cycles. All parameters recovered fully to preswitch values within 5-10 s. Table 1 shows myocardial function during baseline.

First exposure to LFI or Hyp. Although myocardial performance decreased more during LFI than during Hyp as expected (25), the initial rates in LVDP decline were similar $(311 \pm 25$ vs. $300 \pm 27 \mathrm{mmHg} / \mathrm{s}$, respectively; NS). When hearts were exposed to LFI, the changes in LVDP and $\mathrm{dP} / \mathrm{d} t_{\max }$ were monophasic; they usually leveled off within 1-2 min (Fig. 1, left, solid lines). In contrast, when hearts were exposed to Hyp, the changes were biphasic (Fig. 1, left, dashed lines; $P<0.001$ vs. LFI), since a transient increase and a slower decrease followed an early fast decline $(\sim 20 \mathrm{~s})$. HR was not significantly different during LFI and Hyp. Diastolic contracture was more pronounced in Hyp than in LFI hearts $(P<0.001)$.

Table 1. Myocardial performance during baseline perfusion

\begin{tabular}{lc}
\hline \multicolumn{1}{c}{ Parameter } & Value \\
\hline Heart rate, beats/min & $276 \pm 10$ \\
Developed pressure, $\mathrm{mmHg}$ & $144 \pm 5$ \\
$\mathrm{dP} / \mathrm{d} t_{\text {max }}, \mathrm{mmHg} / \mathrm{s}$ & $4,643 \pm 182$ \\
End-diastolic pressure, $\mathrm{mmHg}$ & $10.7 \pm 0.6$ \\
Perfusion pressure, $\mathrm{mmHg}$ & $106 \pm 8$ \\
Resistance, $\mathrm{mmHg} \cdot \mathrm{min} \cdot \mathrm{ml}^{-1}$ & $6.8 \pm 0.2$ \\
Venous $\mathrm{PO}_{2}, \mathrm{mmHg}$ & $198 \pm 13$ \\
$\mathrm{Heart}_{\text {wet weight, } \mathrm{mg}}$ & $1,078 \pm 31$ \\
$\mathrm{H}_{2} \mathrm{O}$ content, $\%$ & $89.2 \pm 0.7$ \\
\hline
\end{tabular}

Values are means $\pm \mathrm{SE} ; n=26$ hearts. $\mathrm{dP} / \mathrm{d} t_{\max }$, maximal rate of pressure development. Perfusion conditions: flow, $15 \mathrm{ml} / \mathrm{min} ; \mathrm{PO}_{2} 670$ $\mathrm{mmHg}$; volume of intraventricular balloon adjusted to yield an end-diastolic pressure of $\sim 10 \mathrm{mmHg}$. 


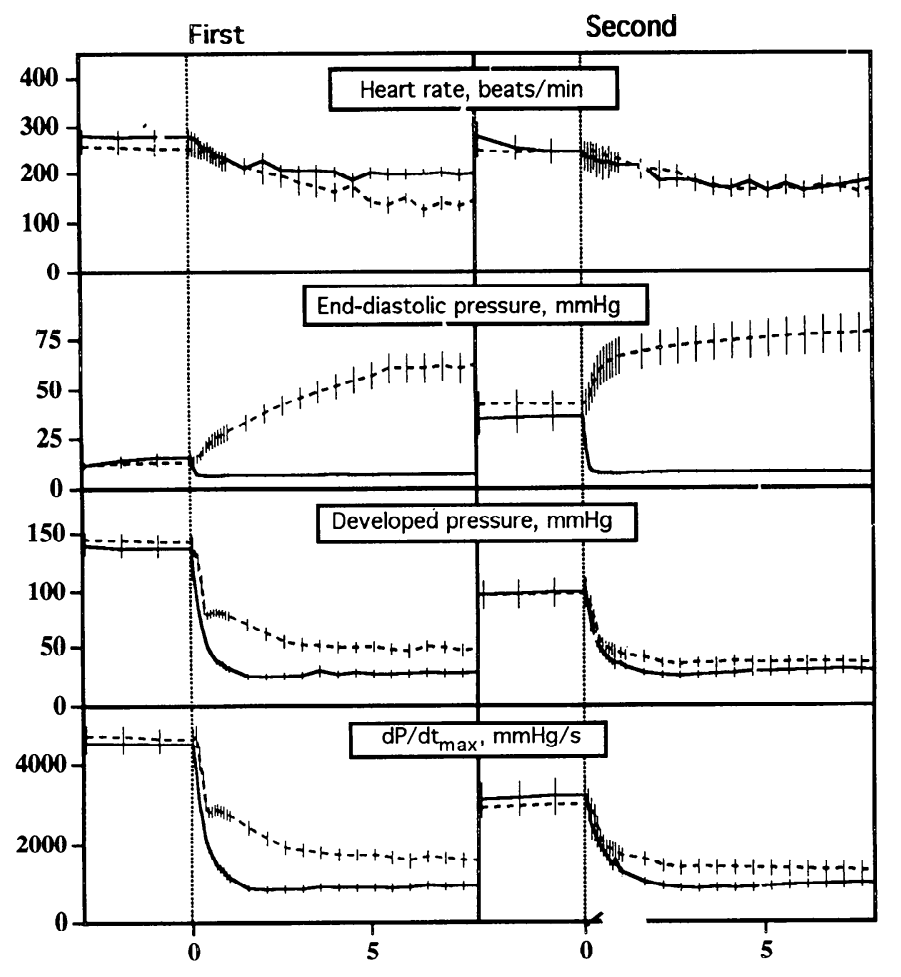

Time, $\min$

Fig. 1. Adaptation of performance to low-flow ischemia or hypoxemia. Time courses of heart rate $(\mathrm{HR})$, end-diastolic pressure, developed pressure, and maximal rate of pressure development $\left(\mathrm{dP} / \mathrm{d} t_{\max }\right)$ after low-flow ischemia (solid line) or hypoxemia (dashed line, $n=13$ hearts/group). First exposure to 10-min $\mathrm{O}_{2}$ shortage (left) was followed by 10 min of reperfusion or reoxygenation (not shown) and by a second exposure to low-flow ischemia or hypoxemia (right). Two-way analysis of variance (ANOVA) for 4 groups yielded $P<0.001$ for all parameters except $\mathrm{HR}(P=0.035)$. Vertical bars, SE.

CPP depended on flow: at the onset of LFI, CPP fell to $15.4 \pm 1.8 \mathrm{mmHg}(\sim 10 \%$ of baseline value) within the time required for the first sampling; it decreased only slightly when Hyp started ( $P<0.001$ vs. LFI; Fig. 2, left). Resistance increased during LFI but decreased when Hyp began $(P<0.001)$. The adaptation of $\mathrm{PO}_{2}$ was faster at the onset of Hyp than of LFI $(P=0.04)$. During sustained LFI, $J_{\mathrm{Lac}}$ increased steadily to $3.4 \pm 0.7$ $\mu \mathrm{mol} / \mathrm{min}$ (Fig. 2, left). During Hyp, however, $J_{\text {Lac }}$ peaked at $13.0 \pm 2.3 \mu \mathrm{mol} / \mathrm{min}(P=0.01 \mathrm{vs}$. LFI $)$ at $t=$ $1.25 \mathrm{~min}$ and then leveled off at a value similar to that measured during LFI $(3.5 \pm 1.3 \mu \mathrm{mol} / \mathrm{min})$.

With respect to baseline (Fig. 3), the tissue content of glycogen decreased by $52 \%$ after $10 \mathrm{~min}$ of LFI $(P=$ $0.05)$ and by $81 \%$ after $\operatorname{Hyp}(P=0.01)$. Ten minutes of LFI did not cause significant changes in the other metabolic parameters, in agreement with previous findings (26). In contrast, 10 min of Hyp did affect these variables, which include ATP, phosphocreatine, energy charge, IMP, and the sum of adenine nucleotides and purines (Fig. 3).

First recovery. Table 2 shows recovery in myocardial function after the first exposure to LFI or Hyp. Except for HR, the recovery after Hyp was slightly less than after LFI (NS).
Second exposure to LFI or Hyp. After recovery from the first intervention, hearts were exposed again to LFI or Hyp (Figs. 1 and 2, right). None of the parameters measured showed significant changes between the first and second periods of LFI. Therefore, the second exposure to LFI caused responses essentially similar to those observed during the first. In contrast, the second exposure to Hyp clearly elicited different responses: 1) decreases in LVDP and $\mathrm{dP} / \mathrm{d} t_{\max }$ were monophasic without marked transient rises in these variables $(P \leq$ 0.005 vs. 1st exposure to Hyp, NS vs. 2nd exposure to LFI); 2) rate of LVDP changes was slower (154 \pm 15 $\mathrm{mmHg} / \mathrm{s} ; P=0.05$ vs. 1 st exposure to Hyp); and 3$) J_{\text {Lac }}$ peak was lower $(7.7 \pm 2.5 \mu \mathrm{mol} / \mathrm{min} ; P<0.05 \mathrm{vs}$. 1 st exposure to Hyp) and similar to that during LFI exposure. Other characteristics were similar during first and second exposures to Hyp. These include CPP, resistance, and EDP, which remained different from the pattern observed during LFI $(P<0.001)$. Overall, with the second reduction in $\mathrm{O}_{2}$ supply, Hyp hearts tended to behave similarly to LFI hearts. Nevertheless, other variables related to flow were still different.

Second recovery. Table 2 shows myocardial performance after the second reduction in $\mathrm{O}_{2}$ supply. Although the second exposure to LFI did not cause appreciable changes, such an exposure to Hyp induced a further depression $(P=0.05)$ of myocardial performance for LVDP and $\mathrm{dP} / \mathrm{d} t_{\max }$.

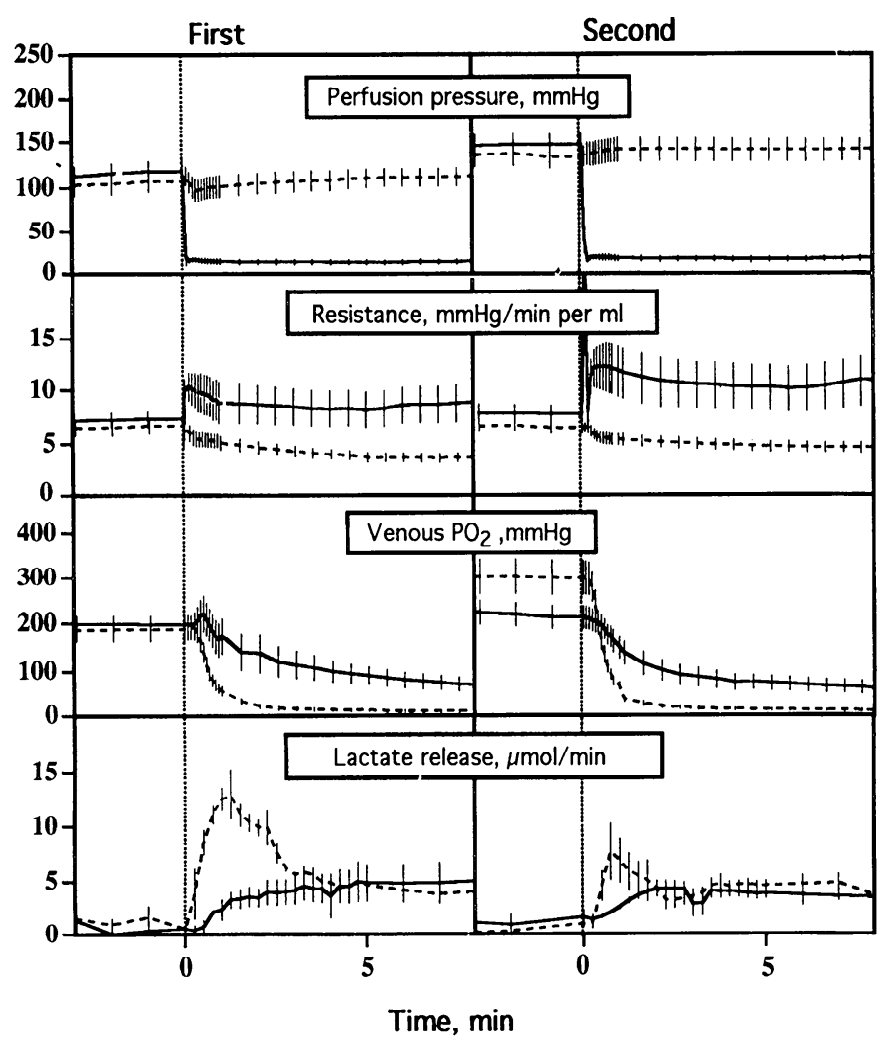

Fig. 2. Adaptation of performance to low-flow ischemia or hypoxemia. Time course of coronary perfusion pressure, resistance, venous $\mathrm{PO}_{2}$, and net lactate release. Same conditions as in Fig. 1. Two-way ANOVA for 4 groups yielded $P<0.001$ for all parameters. 
Glycogen

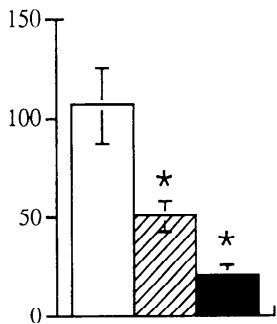

Purine derivatives

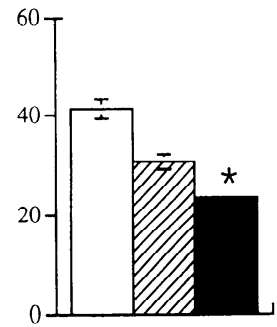

ATP

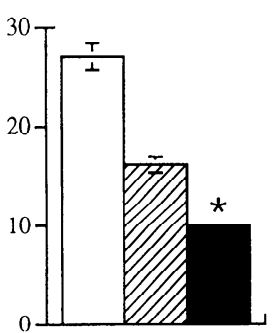

Energy charge

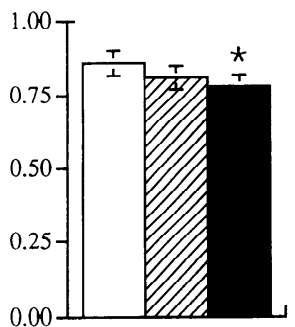

Inosine-5'-monophosphate

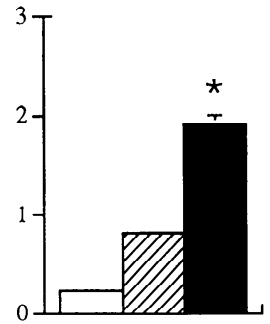

Phosphocreatine

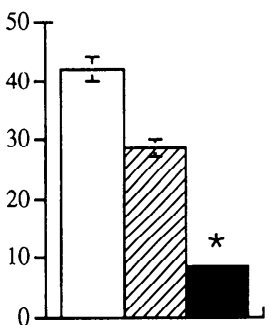

Fig. 3. Tissue metabolites at end of baseline (open bars) and of first exposure to low-flow ischemia (hatched bars) or hypoxemia (solid bars). Data are expressed in $\mu \mathrm{mol} / \mathrm{g}$ dry tissue except for glycogen (mg/g dry wt) and energy charge (nondimensional). One-way ANOVA for 3 groups yielded $P \leq 0.04$. Means $\pm \mathrm{SE}$ are given; $n=4$ hearts/group. *Significant difference from baseline.

\section{DISCUSSION}

Acute responses to LFI and Hyp. The myocardial adaptations to LFI and Hyp were different. Although the changes in LVDP and $\mathrm{dP} / \mathrm{d} t_{\max }$ at the onset of LFI were fast and monophasic, those observed during Hyp were similar to the LFI changes during the initial $20 \mathrm{~s}$ only. Transient increases in pressure during Hyp followed, however. When reperfused or reoxygenated hearts were exposed again to LFI or Hyp, the responses to LFI and Hyp were superimposable and similar to those observed during the first exposure to LFI (obviously except flow-related parameters, i.e., CPP, EDP, and resistance). Comparable rates of change during the initial $20 \mathrm{~s}$ of Hyp and LFI strongly suggest that the main factor acutely limiting myocardial performance

Table 2. Myocardial performance at end of recovery from first and second exposure to low-flow ischemia or hypoxemia

\begin{tabular}{|c|c|c|c|c|}
\hline \multirow[b]{2}{*}{ Parameter } & \multicolumn{2}{|c|}{$\begin{array}{l}\text { After Low-Flow } \\
\text { Ischemia }\end{array}$} & \multicolumn{2}{|c|}{ After Hypoxemia } \\
\hline & $1 \mathrm{st}$ & 2nd & $1 \mathrm{st}$ & 2 nd \\
\hline $\begin{array}{l}\text { Heart rate, } \% \text { of base- } \\
\text { line }\end{array}$ & $98 \pm 1$ & $95 \pm 1$ & $96 \pm 3$ & $91 \pm 3$ \\
\hline $\begin{array}{l}\text { Developed pressurc, } \% \\
\text { of baseline }\end{array}$ & $83 \pm 5$ & $74 \pm 5$ & $68 \pm 5^{*}$ & $51 \pm 5 \dagger$ \\
\hline $\mathrm{dP} / \mathrm{d} t_{\max }, \%$ of baseline & $75+4$ & $64 \pm 5$ & $59 \pm 4 *$ & $43 \pm 5 \dagger$ \\
\hline $\begin{array}{l}\text { Increase of end-diastolic } \\
\text { pressure over base- } \\
\text { line value, } \mathrm{mmHg}\end{array}$ & $25 \pm 7$ & $28 \pm 7$ & $31 \pm 7$ & $49 \pm 9$ \\
\hline $\begin{array}{l}\text { Increase of perfusion } \\
\text { pressure over base- } \\
\text { line value, } \mathrm{mmHg}\end{array}$ & $41 \pm 12$ & $43 \pm 12$ & $27 \pm 12$ & $40 \pm 13$ \\
\hline
\end{tabular}

Values are means $\pm \mathrm{SE} ; n=13$ hearts. For perfusion conditions, see Table 1. One-way analysis of variance yielded $P<0.001$ for developed pressure and $\mathrm{dP} / \mathrm{d} t_{\max }$, and NS for the other parameters. No significant differences were detected between 1st and 2nd exposures to low-flow ischemia and hypoxemia. Significance vs. low-flow ischemia in the corresponding situation: $* P=0.05 ; \dagger P=0.001$. could be $\mathrm{O}_{2}$ availability, in agreement with studies in dog gastrocnemius muscle (15). Later, flow-related events become predominant, taking over control of myocardial performance. The critical time, when these overriding events prevail over those related to $\mathrm{O}_{2}$ availability, depends on experimental model, flow, and energy supply-to-demand ratio.

The $\mathrm{O}_{2}$ supply during baseline $\left(14.1 \mu \mathrm{mol} \cdot \mathrm{min}^{-1}\right.$. heart ${ }^{-1}$ or $\left.13.1 \mathrm{\mu mol} \cdot \mathrm{min}^{-1} \cdot \mathrm{g}^{-1}\right)$ was slightly higher than that of hearts in vivo $\left(8.5-10.1 \mu \mathrm{mol} \cdot \mathrm{min}^{-1} \cdot \mathrm{g}^{-1}\right)$, assuming a flow of $0.70-0.85 \mathrm{ml} \cdot \mathrm{min}^{-1} \cdot \mathrm{g}^{-1}$, a hemoglobin concentration of $155 \mathrm{~g} / \mathrm{l}$, and a $98 \% \mathrm{O}_{2}$ saturation at $100 \mathrm{mmHg} \mathrm{PO}_{2}$. Therefore we suppose that $\mathrm{O}_{2}$ supply during LFI or Hyp was reduced to $-1 / 10$ of the in vivo value. This condition was associated with downregulation of myocardial activity during LFI due to low coronary flow, known to depress lactate washout, inhibiting glycolysis by cell acidification (25). The poor ability of Hyp hearts to rephosphorylate ADP to ATP, due to excessive energy demand with respect to supply, leads to extensive formation of ATP catabolites, some of which permeate the cell membrane. They are therefore lost under high-flow conditions (26). The higher tissue content of IMP also reflects the greater metabolic derangement in Hyp hearts (2). Relatively low flow in LFI hearts leads to downregulation of cardiac function and a better maintenance of high-energy phosphates (26), which in turn improves recovery. The duration of exposure to LFI or Hyp is sufficient to allow hearts to develop different extents of reperfusion injury, as in studies in which the shortage of $\mathrm{O}_{2}$ supply lasted 20 $\min (27)$.

Time-resolved analysis of regulatory pathways. The time resolution of the patterns observed with exposure to LFI and Hyp allows the identification of pathways asynchronous with other phenomena observed. If the adaptation of a biological system to an external stimulus is monophasic, then a single factor probably limits 
the whole process. For example, intracellular $\mathrm{Ca}^{2+}$ transients may theoretically play a significant role, since contractile dysfunction is related to changes in $\mathrm{Ca}^{2+}$ handling and myofilament $\mathrm{Ca}^{2+}$ sensitivity during Hyp and global no-flow ischemia, respectively (16). However, alterations in $\mathrm{Ca}^{2}$ transients usually occur on a time scale much longer than that observed in this study. Presumably, they are a consequence, not the cause, of the altered metabolic status in skeletal and heart muscles (18). In Hyp hearts, the steady increase in EDP, which appears to reflect the long-term changes in the $\mathrm{Ca}^{2-}$ transient secondary to glycogen and ATP depletion (17), supports this hypothesis. It is unlikely that EDP changes are linked to stress-strain relations (3), since the time course of this variable does not correspond to that of resistance.

In principle, the biphasic adaptation at the onset of Hyp may be due to disturbances secondary to reduced transmural tissue pressure. This attenuation could depress force development by affecting alignment of and tension on the myofibril. However, the adaptation of CPP and resistance to LFI is fast $(<5 \mathrm{~s})$ compared with adaptation to Hyp. In the latter case, early changes do not occur, ruling out primary involvement of coronary perfusion inhomogeneities due to hypoxic vasodilation. Short-term coronary reactivity may be due to the garden-hose effect (32), since the associate "erectile" effect increases myocardial wall tone and, therefore, EDP. However, CPP and resistance follow reproducible patterns from the first to the second exposure to Hyp. In contrast, the patterns of myocardial contractility are strikingly different. Therefore explaining the different dynamics of performance adjustment with different coronary reactivities is difficult.

The $J_{\text {Lac }}$ peak, observed during the first exposure to Hyp, coincided with the transient increases in myocardial activity. Furthermore, $J_{\text {Lac }}$ peaks did not occur during LFI; they were much lower with the second exposure to Hyp, corresponding to reduced increases in function under these conditions. It is thus tempting to associate transient increases in myocardial function with bursts of lactate release, indicating reduced ATP production due to $\mathrm{O}_{2}$ limitation (12). We found no evidence for a transient nonaerobic energy source sustaining ATP production at the onset of LFI. This fits the criteria of time correspondence among the various patterns observed and of quantitative consistency. Indeed, glycolytic bursts can already occur within $5 \mathrm{~s}$ after a work jump. In addition, glycogenolysis can be maximally active within $30 \mathrm{~s}(5)$ due to rapid activation of fructokinase and phosphorylase b (1), and glycolytic ATP production may account for up to one-half of the total energy required by Hyp hearts (25).

Energy stores. What is the role of the various energy stores to supply energy at the onset of $\mathrm{O}_{2}$ shortage? The amount of $\mathrm{O}_{2}$ stored in dissolved form or bound to myoglobin is irrelevant, since interruption of $\mathrm{O}_{2}$ supply affects $\mathrm{O}_{2}$ uptake within $4 \mathrm{~s}$ (10). Full assessment of the acute changes in aerobic metabolism, i.e., within seconds, is difficult because of the low response time of the $\mathrm{PO}_{2}$ electrode (see above). However, the fast response of venous $\mathrm{PO}_{2}$ at the onset of Hyp compared with the slow response of performance suggests that changes in aerobic metabolism are not crucial in our model. In fact, as shown earlier, aerobic metabolism does not vary in LFI and Hyp hearts at any energy demand level (25).

The intracellular stores of phosphocreatine are sufficient to support myocardial activity for $<3-8 \mathrm{~s}$. These values are based on the reported ATP turnover rate during LFI and Hyp (25) and the changes observed in tissue ATP and phosphocreatine levels (26). The absence of fatty acids in the medium prevents mobilization of triacylglycerol or fatty acid stores, because these stores remain unchanged in isolated hearts subjected to 90 min of ischemia (31).

Despite the high glucose concentration in the medium, which should have saturated the glucose transport system (34), our hearts used substantial amounts of glycogen during Hyp. When we again exposed reoxygenated hearts to Hyp, they therefore depended to a larger extent on exogenous glucose. Fast glycogen utilization is consistent with accelerated glycogenolysis when fatty acids are absent from the medium (22). Our data are also consistent with computer simulations. These predict that the rapid increase in energy demand is first met by glycogen breakdown, followed by increased glucose uptake from the perfusion fluid (1).

Implications and limitations of this study. Increased tissue glycogen improves the metabolic status by maintaining ATP during anaerobiosis (7) and by retarding loss of ATP and its catabolites (29). It provides an explanation for the worse recovery after Hyp than after LFI. Tissue glycogen may be crucial in the early phases of $\mathrm{O}_{2}$ shortage, since it fuels glycolysis, further blunting myocardial downregulation.

A limitation of this study is that myocardial performance in the two study groups was not the same before the second reduction in $\mathrm{O}_{2}$ supply, since recoveries from the first intervention are different. We minimized this problem by halving the duration of LFI and Hyp with respect to that used in our previous studies $(26,27)$ to reduce functional depression in Hyp hearts. We cannot exclude that the remaining differences, even if small, before the second intervention have affected the results obtained.

In the present study, we did not use erythrocytes in the perfusion medium for several reasons. First, we wanted to exclude nonspecific phenomena related to capillary blood clotting and leukocyte infiltration. Second, with erythrocytes, perfusion is heterogeneous, because of expected differences in capillary hematocrit, erythrocyte transit times (23), spacing within the capillary (9), and velocities (28) during normal perfusion, LFI, and Hyp. Heterogenous perfusion results in different $\mathrm{O}_{2}$ unloading rates and unpredictable local $\mathrm{O}_{2}$ supply, which would have been detrimental in this study. Third, the relatively slow erythrocyte $\mathrm{O}_{2}$ offloading kinetics (11) would complicate understanding of the second-to-second dynamics of cardiac adaptation to LFI and Hyp. Fourth, unpredictable shifts of the $\mathrm{O}_{2}$-hemoglobin dissociation curve along the capillary due to changing local conditions of $\mathrm{pH}, \mathrm{PCO}_{2}$, and 
lactate (33) make it difficult to reduce $\mathrm{O}_{2}$ supply by exactly $90 \%$, a necessary condition to compare LFI and Hyp.

Finally, we want to caution against the transfer of the rationale underlying simple biochemical in vitro processes to complex in vivo systems.

In conclusion, we provide evidence that, at the beginning of ischemia, a single factor, presumably the $\mathrm{O}_{2}$ availability, does limit myocardial performance, which remains undisturbed up to $10 \mathrm{~min}$. In contrast, $\sim 20 \mathrm{~s}$ after the start of hypoxemia, glycolytic ATP production could partially override low $\mathrm{O}_{2}$ availability by providing the bulk of the energy needed. During the second restriction of $\mathrm{O}_{2}$ supply, the $\mathrm{O}_{2}$ availability appears the only factor limiting performance in both ischemic and hypoxemic hearts.

We acknowledge the expert technical help of Drs. S. Casalini, S. Costa, and S. Sommaruga.

This study was supported by Target Project Biotecnologie e Biostzumentazione, Consiglio Nazionale delle Ricerca, Rome, Italy.

Address for reprint requests: M. Samaja, Dept. of Biomedical Science and Technology, Palazzo Lita, Via Fratelli Cervi 93, Milan I-20090, Italy.

Received 17 October 1995; accepted in final form 30 May 1996.

\section{REFERENCES}

1. Achs, M. J., D. Garfinkel, and L. H. Opie. Computer simulation of metabolism of glucose-perfused rat heart in a work-jump. Am. J. Physiol. 243 (Regulatory Integrative Comp. Physiol. 12) R389-R399, 1982

2. Achterberg, P. W., A. S. Nieukoop, B. Schoutsen, and J. W. de Jong. Different ATP catabolism in reperfused adult and newborn rat hearts. Am. J. Physiol. 254 (Heart Circ. Physiol. 23): H1091-H1098, 1988

3. Allaart, C. P., P. Sipkema, and N. Westerhof. Effect of perfusion pressure on diastolic stress-strain relations of isolated rat papillary muscle. Am. J. Physiol. 268 (Heart Circ. Physiol. 37): H945-H954, 1995.

4. Carr, R. S., and J. M. Neff. Quantitative semi-automated enzymatic assay for tissue glycogen. Comp. Biochem. Physiol. B Biol. Sci. 77: 447-449, 1984.

5. Connett, R. J., 'T. E. J. Gayeski, and C. R. Honig. Energy sources in fully aerobic rest-work transitions: a new role for glycolysis. Am. J. Physiol. 248 (Heart Circ. Physiol. 17): H922H929, 1985.

6. Cunningham, M. J., C. S. Apstein, E. O. Weinberg, W. M. Vogel, and B. H. Lorell. Influence of glucose and insulin on the exaggerated diastolic and systolic dysfunction of hypertrophied rat hearts during hypoxia. Circ. Res. 66: 406-415, 1990.

7. Dietrich, D. L. L., and G. Elzinga. ATP formation and energy demand in anoxic heart muscle of the rabbit. $\Lambda \mathrm{m}$. J. Physiol. 263 (Heart Circ. Physiol. 32): H526-H532, 1992.

8. Eijgelshoven, M. H. J., J. H. G. M. van Beek, I. Mottet, M. G. J. Nederhoff, C. J. A. van Echteld, and N. Westerhof. Cardiac high-energy phosphates adapt faster than oxygen consumption to changes in heart rate. Circ. Res. 75: 751-759, 1994.

9. Federspiel, W. J., and A. S. Popel. A theoretical analysis of the effect of the particulate nature of blood on oxygen release in capillaries. Microvasc. Res. 32: 164-189, 1986.

10. Gayeski, T. E. J., and C. R. Honig. Intracellular $\mathrm{PO}_{2}$ in individual cardiac myocytes in dogs, cats, rabbits, ferrets, and rats. Am. J. Physiol. 260 (Heart Circ. Physiol. 29): H522-H531, 1991.

11. Gutierrez, G. The rate of oxygen release and its effect on capillary $\mathrm{O}_{2}$ tension: a mathematical analysis. Respir. Physiol. 63: 79-96, 1986

12. Hak, J. B., J. H. G. M. van Beek, M. H. van Wijhe, and N. Westerhof. Dynamics of myocardial lactate efflux after a step in heart rate in isolated rabbit hearts. Am. J. Physiol. 265 (Heart Circ. Physiol. 34): H2081-H2085, 1993.
13. Hochachka, P. W., and G. O. Matheson. Regulating ATP turnover rates over broad dynamic work ranges in skeletal muscles. J. Appl. Physiol. 73: 1697-1703, 1992.

14. Hogan, M. C., S. Nioka, W. F. Brechue, and B. Chance. A ${ }^{31} \mathrm{P}-\mathrm{NMR}$ study of tissue respiration in working dog muscle during reduced $\mathrm{O}_{2}$ delivery conditions. J. Appl. Physiol. 73: 1662-1670, 1992.

15. Hogan, M. C., R. S. Richardson, and S. S. Kurdak. Initial fall in skeletal muscle force development during ischemia is related to oxygen availability. J. Appl. Physiol. 77: 2380-2384, 1994.

16. Kihara, Y., W. Grossman, and J. P. Morgan. Direct measurement of changes in intracellular calcium transients during hypoxia, ischemia and reperfusion of the intact mammalian heart. Circ. Res. 65: 1029-1044, 1989.

17. Kusuoka, H., and E. Marban. Mechanism of the diastolic dysfunction induced by glycolytic inhibition. J. Clin. Invest. 93 1216-1223, 1994.

18. Lee, J. A., and D. G. Allen. The effects of repeated exposure to anoxia on intracellular calcium, glycogen and lactate in isolated ferret heart muscle. Pfluegers Arch. 413: 83-89, 1988.

19. Lee, J. A., and D. G. Allen. Mechanisms of acute ischemic contractile failure of the heart. Role of intracellular calcium. J. Clin. Invest. 88: 361-367, 1991

20. Mast, F., and G. Elzinga. Oxidative and glycolytic ATP formation of rabbit papillary muscle in oxygen and nitrogen. Am. J. Physiol. 258 (Heart Circ. Physiol. 27): H1144-H1150, 1990.

21. Monti, L. D., P. E. Sandoli, S. Costa, V. C. Phan, and P. M. Piatti. Fluorimetric methods for the measurement of intermediate metabolites (lactate, pyruvate, alanine, $\beta$-hydroxybutyrate, glycerol) using a COBAS FARA centrifugal analyser. J. Autom. Chem. 15: 177-181, 1993.

22. Neely, J. R., C. F. Whitfield, and H. E. Morgan. Regulation of glycogenolysis in hearts: effects of pressure development, glucose and FFA. Am. J. Physiol. 219: 1083-1088, 1970.

23. Rose, C. P., and C. A. Goreski. Limitation of tracer oxygen uptake in the canine coronary circulation. Circ. Res. 56: 5770, 1985.

24. Rovetto, M. J., J. T. Whitmer, and J. R. Neely. Comparison of the effects of anoxia and whole heart ischemia on carbohydrate utilization in isolated working rat hearts. Circ. Res. 32: 699-711, 1973.

25. Samaja, M., S. Casalini, S. Allibardi, A. Corno, and S. L. Chierchia. Regulation of biocnergetics in $\mathrm{O}_{2}$-limited isolated rat hearts. J. Appl. Physiol. 77: 2530-2536, 1994.

26. Samaja, M., R. Motterlini, S. Allibardi, S. Casalini, G. Merati, A. Corno, and S. L. Chierchia. Myocardial metabolism and function in acutely ischemic and hypoxemic isolated rat hearts. J. Mol. Cell. Cardiol. 27: 1213-1218, 1995.

27. Samaja, M., R. Motterlini, F. Santoro, G. Dell'Antonio, and A. Corno. Oxidative injury in reoxygenated and reperfused hearts. Free Radical Biol. Med. 16: 255-262, 1994.

28. Sarelius, I. H. Microcirculation in striated muscle after acute reduction in systemic hematocrit. Respir. Physiol. 78: 7-17, 1989.

29. Schneider, C. A., and H. Taegtmeyer. Fasting in vivo delays myocardial cell damage after brief periods of ischemia in the isolated working rat heart. Circ. Res. 68: 1045-1050, 1991.

30. Stainsby, W. N., W. F. Brechue, D. M. O'Drobinak, and J. K. Barclay. Effects of ischemic and hypoxic hypoxia on $\dot{\mathrm{V}}_{2}$ and lactic acid output during tetanic contractions. J. Appl. Physiol. 68: $574-579,1990$

31. Van Bilsen, M., G. J. van der Vusse, P. H. M. Willemsen, T. H. M. Roemen, and R. S. Reneman. Lipid alterations in isolated-working rat hearts during ischemia and reperfusion: its relation to myocardial damage. Circ. Res. 64: 304-314, 1989.

32. Vogel, W. M., C. S. Apstein, L. L. Briggs, W. H. Gaasch, and J. Ahn. Acute alterations in left ventricular diastolic chamber stiffness. Role of the "erectile" affect of coronary arterial pressure and flow in normal and damaged hearts. Circ. Res. 51: 465-478, 1982.

33. Wasserman, K., J. E. Hansen, and D. Y. Sue. Facilitation of oxygen consumption by lactic acidosis during exercise. News Physiol. Sci. 6: 29-34, 1991.

34. Zweier, J. L., and W. E. Jacobus. Substrate-induced alterations of high energy phosphate metabolism and contractile function in the perfused heart. J. Biol. Chem. 262: 8015-8021, 1987. 